\title{
La Ciudadanía como Co-construcción de Espacios de Participación en lo Público
}

\section{Resumen}

Ser ciudadano significa tener consciencia de su rol transformador y emancipador, comprometido con la igualdad y partícipe de un proyecto colectivo. La nueva ciudadanía no difiere de ello pero le agrega el componente de co-construcción colectiva que posibilita la ampliación de las articulaciones entre sí y con el Estado para ejercer ciudadanía desde lo local permitiendo potenciar canales de participación y de ejercicio de la ciudadanía configurando un nuevo escenario co-participativo y más democrático.

Palabras Clave: Co-ciudadanía. Participación. Democracia. Gobiernos locales. Políticas públicas.

Citizenship as a co-construction of spaces for participation in the public sphere

\section{Abstract}

Exercising citizenship means to be aware of one's own transformative and emancipatory role, to be committed to equality and to sharing a collective project.

\footnotetext{
*Facultad de Ciencias Sociales y Económicas, Universidad Católica del Maule (Chile). E-mail: cmejias@ucm.cl

${ }^{* *}$ Facultad de Ciencias Sociales y Económicas, Universidad Católica del Maule (Chile). E-mail: phenriquez@ucm.cl
} 
The new citizenship does not diverge from it, although it adds the component of a collective co-construction. It allows for expanding relationships - both mutual and with the State - as well as for exercising citizenship at the local level, by strengthening the channels for civic participation and thus establishing a new coparticipatory and more democratic setting.

Keywords: Co-citizenship. Democracy. Participation. Local governments. Public policy.

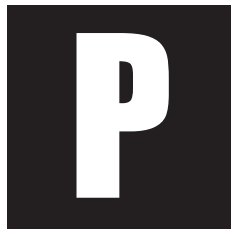

ensar en el ciudadano, la ciudadanía o la participación en la sociedad actual es una tarea asaz difícil, más si deseamos entender las transformaciones sociopolíticas y culturales en tiempos de cambios complejos y globales. Todo ello exige un intento de comprensión de un nuevo espacio democrático, que paradojalmente pareciera prescindir tanto del espacio como de los ciudadanos. Este espacio, como toda esfera social, es un lugar de confrontación de ideas e intereses económicos y políticos, en el que se revelan fuerzas y movimientos sociales que nos interrogan e interpelan acerca de una permanente construcción sociocultural. Democracia, 'glocalización' y participación se constituyen así en un trío problemático que da cuenta de novedosas formas de comunicación e información ciudadana, pero también de nuevas exclusiones, exigencias, derechos y formas participativas.

Para algunos estudiosos, este escenario permitirá, además, "encauzar los conflictos, avanzar en la resolución de los problemas sociales y generar capacidades institucionales adecuadas para movilizar constructivamente las energías de las respectivas sociedades (Molina, 2007, apud Tesoro, 2007 p. 174). 
Más allá de que esto sea posible o no, si llevamos este espacio de disputa que se presenta a escala 'glocal' a un espacio más restringido como son los gobiernos locales, veremos que se reproducen, con un mayor grado, las mismas problemáticas pero con un impacto social aumentado. Las representaciones de ciudadanía y democracia que se construyen no se corresponden con un proceso lineal, ni apuntan en una sola dirección, ni desarrollan verdaderos espacios de participación, ni poseen intereses comunes ni una plataforma común ${ }^{1}$. Las representaciones de ciudadanía son más bien ambivalentes, heterogéneas, móviles, inciertas, inestables, complejas, excluyentes o meramente informativas dependiendo de la ubicación individual y grupal en el conjunto diferenciado de poderes y marginaciones presentes en el territorio local.

Así, la ciudadanía puede ser vista desde dos perspectivas. Por una parte, del poder, como un conjunto que lucha por el reconocimiento y conquista de derechos en un espacio de conflicto en el que se busca hipotéticamente superar las desigualdades; y, por la otra, del poder y la ciudadanía, como el espacio "ideal" de libertad y ejercicio de derechos y deberes democráticos que trascienden los límites de una institucionalidad y una legislación estatal y nacional. Estas diferentes representaciones y significaciones de la ciudadanía convergen, sin embargo, como espacio en construcción de otra esfera social que interroga el declive y agotamiento del modelo tradicional. Este nuevo orden temporal y espacial de experiencias, expresa, de algún modo, la lucha por la conquista de espacios y poder político, así como aboga por una ampliación de derechos humanos y ciudadanos y una real participación democrática.

\footnotetext{
${ }^{1}$ Aun cuando la constitución política de Chile establece que los gobiernos locales, es decir, las Municipalidades como corporaciones autónomas y de derecho público, con personalidad jurídica y patrimonio propio, tienen la finalidad de satisfacer las necesidades de la comunidad local y asegurar su participación en el progreso económico, social y cultural de la comuna. La organización de la administración local, sus funciones, atribuciones y competencias se encuentran reguladas en la Ley Orgánica Constitucional de Municipalidades, Ley 18.695.
} 
No estamos ante una de las tantas crisis coyunturales del modelo capitalista de desarrollo, sino ante el reclamo y expresiones de nuevas formas de organización social, económica y política. Este nuevo mundo que está emergiendo, es un mundo donde las interacciones estarán mediatizadas en escenarios tanto físicos como virtuales, donde las personas conformarán, supuestamente, una gran red que creará nuevas culturas y demarcaciones en el campo social y político (Quintanilla; Aibar, 2002, p.89).

Lo fundamental, más allá de cuestionar los planteamientos que apuntan a la deificación de la participación, es proponer caminos de convergencia y rescate del 'saber de la ciudadanía' (Arteta, 2008). Por lo mismo, este escrito, parte del proyecto "co-construcción ciudadana, participación y gobiernos locales", pretende explorar cómo se reconfiguran los ciudadanos y cómo la nueva ciudadanía debe ser un ejercicio de co-construcción que busca la co-participación en la elaboración de las políticas públicas en el espacio local/global.

\section{Redefiniendo al Ciudadano y la Ciudadanía}

Actualmente este problema sigue siendo una grave inconsistencia de los sistemas democráticos. Aunque no es la única, puesto que también se ha insistido, en las últimas décadas, en hacer prevalecer una espuria universalidad y una falsa igualdad que conlleva esa noción de ciudadanía. Debemos agregar que, a propósito de la asimilación inherente al concepto de ciudadanía, se ha diluido la relación entre sujeto político² e individuo y

\footnotetext{
${ }^{2}$ Ya en el siglo XVIII, desde posiciones feministas y antiesclavistas, autores como el Marqués de Condorcet u Olimpia de Gouges impugnaron esta caracterización, y lo hicieron señalando las contradicciones internas a la noción de sujeto como ser autoconstituyente (de la que se deriva la de sujeto político); sin embargo, nunca se cuestionó la idea de naturaleza humana común, a la que tanto unos como otros acudieron. Unos para impugnar los privilegios políticos de la aristocracia, otros para impugnar los nuevos privilegios políticos del ciudadano. Todos, pues, emplearon la idea de que los derechos eran lógica y genéticamente anteriores a la política, dado que emanaban de una supuesta naturaleza humana única y fija.
} 
cuyo problema no es sólo el supuesto individuo neutral (que virtualmente podía ser cualquiera, pero resultó ser varón, blanco, anglohablante, heterosexual, propietario y cristiano), sino que la ideología liberal moderna lo concebía como un átomo social independiente y desvinculado de los demás; una entidad cuya identidad se explicaba por remisión a sí mismo como fuente. Un ser atemporal, acrítico, individual y desarraigado.

La sociedad sigue funcionando con esa lógica y los ciudadanos están convencidos que esa pareciese ser la única forma de ser en lo social, político o económico. Por lo mismo, nuestra concepción de ciudadanía y ciudadano partirá, en primer lugar, de la idea de que los seres humanos no son independientes, es decir, que adquieren su identidad (también la política) en un marco colectivo, o sea, en permanente interacción con otros, en los cuales ve reflejado no sólo sus necesidades, identidades y evaluaciones individuales, sino también proyecta sus desafíos y satisfacciones ciudadanas a través de una visión/acción cooperativa-colectiva. Y en segundo lugar, el problema es cómo entender ese marco colectivo - en este nuevo escenario glocal (ya sea físico o virtual) - y cómo, desde ahí, se articula la política pública para una participación real.

Los nuevos escenarios colocan en el centro del desarrollo los componentes del conocimiento y la información construidos por las trasnacionales; el papel fundamental de los procesos de mundialización provocan importantes modificaciones en el quehacer político y en la imagen de lo público; la fluidez de la circulación del dinero, la información, las imágenes y los símbolos diluyen la idea de nación o de fronteras nacionales e impactan la tradicional división entre lo público y lo privado. Como sostiene García Canclini (1995, p. 87):

No fueron tanto las revoluciones sociales [...] como el crecimiento vertiginoso de las tecnologías audiovisuales de comunicación lo que volvió patente de qué manera venían cambiando desde el siglo pasado el desarrollo de lo público 
y el ejercicio de la ciudadanía. Pero éstos fueron desplazando el desempeño ciudadano hacia las prácticas del consumo, muchas preguntas propias de los ciudadanos se contestan más en el consumo privado de bienes y de los medios masivos que espacios públicos.

Todos estos cambios alteran también las formas del ejercicio ciudadano, que se expanden a prácticas cotidianas relacionadas con el uso de la información para el logro de conquistas personales o grupales. La redefinición del ser social, sus derechos y el uso del espacio real, mediático o virtual permitirá constituir a una persona en actor frente a otros actores sociales. Ello implica intentar definir al nuevo ciudadano; al co-ciudadano. Existen innumerables definiciones de ciudadanía, sin embargo, partiremos agrupándolas dentro del marco ideológico sobre el cual se han construido y, desde ahí, establecer nuestra propuesta de cómo entender esta nueva ciudadanía y cómo se articula con las políticas públicas.

Para efectos de este escrito, las hemos agrupado en cuatro marcos. El primero es el Jurídico-Liberal, en el que la ciudadanía es entendida como un conjunto de normas jurídicas, estatus o doctrina según la cual el Estado reconoce jurídicamente al ciudadano y, por ende, éste debe reconocerse como tal. El segundo es el Reivindicativo Neocapitalista, en el que la ciudadanía es comprendida como innata o contrato social o lucha reivindicativa (sindicatos, medio ambientalistas entre otros) para la consecución de determinadas libertades, dentro del marco del modelo capitalista, necesarias para el desarrollo de las personas. El tercero es el Individualista Neoliberal, que concibe la ciudadanía como vínculo único y exclusivo, como responsabilidad personal, determinada al espacio local o como algo exterior al sujeto, y que concibe la relación Estado-sujeto como trascendente sin necesariamente serlo. Por último, el Universalista Neosocial, que entiende la ciudadanía como el conjunto de todos los derechos fundamentales, como un estatus universal o como una supraciudadanía universal, omnicomprensiva y omnipresente. 
Establecidos los marcos, es interesante, para la discusión y presentación de nuestra propuesta de ciudadanía, revisar algunas definiciones clásicas que responden a estas concepciones. La definición - la más clásica - planteada por Marshall (1992, p. 18) establece que la

Ciudadanía es un status asignado a todos aquellos que son miembros plenos de una comunidad. Todos los que posean dicho status son iguales con respecto a derechos y deberes [...] Clase social, por otro lado, es un sistema de desigualdad. Y también, como ciudadanía, puede basarse en un conjunto de ideales, creencias y valores.

Por su parte, Kymlicka y Norman (1996, p. 2) establecen que el concepto de ciudadanía está íntimamente ligado, por un lado, a la idea de derechos individuales y, por el otro, a la noción de vínculo con una comunidad particular. Es decir, el sujeto es receptor y actor en la lucha por los derechos propios en la dinámica socio-política, y con pertenencia comunitaria. Una definición más tradicional y normativa es la de la UNICEF (2005, p. 14):

[...] entendemos por ciudadano a la persona poseedora de unos derechos y supeditada a unos deberes que ejercita en relación con los demás para promover mejoras a su alrededor. La ciudadanía [...] así entendida se proyecta a cuatro dimensiones: la posesión de unos derechos, la asunción de unas responsabilidades, la relación con el medio y el espíritu de cambio positivo.

Turner (1990), a su vez, establece una clasificación binominal, definiendo así una ciudadanía pasiva, "desde arriba", de responsabilidad del Estado, que representa a una ciudadanía conservadora, y una ciudadanía "desde abajo", proveniente de organizaciones locales autónomas, configurando a una ciudadanía más bien revolucionaria.

Las definiciones establecen que la ciudadanía es un status, o sea, un reconocimiento social y jurídico por el que una persona o ciudadano tiene derechos y deberes por su pertenencia a una comunidad casi siempre 
de base territorial y cultural. Sin embargo, la historia ha demostrado que las normas se cumplen formalmente pero no se asumen, no se internalizan. Es necesario, entonces, considerar que a los derechos de autonomía individual frente al poder del Estado y de participación en las decisiones públicas se agregan finalmente los denominados derechos jurídicos, políticos, sociales y vitales ${ }^{3}$, que responden a los valores de la igualdad, la solidaridad y la no discriminación, de manera de poder comenzar a amalgamar una nueva ciudadanía. Las primeras premisas básicas indican que los "ciudadanos" son iguales entre sí y no se debe distinguir entre ciudadanos de primera, segunda, etc. categoría; en el mismo territorio, sometidos a mismas leyes, todos tienen que ser iguales. La ciudadanía acepta la diferencia, no la desigualdad. Convivir requiere un mínimo de pautas comunes y de tolerancia ante la diversidad. Sin igualdad, por lo menos formal, este compromiso no es posible ${ }^{4}$.

La consolidación de nuevas democracias ha otorgado especial importancia a la concertación política entre los diversos actores para enfrentar el futuro con proyectos de desarrollo sostenible de modo que [l]a deliberación ceda a la autoafirmación de la mayoría hegemónica (Rubio Carracedo, 2007, p. 78). Esto hace que aparezcan hoy en primer plano los derechos de segunda generación ${ }^{5}$. No obstante, la institucionalización de la democracia, si bien

\footnotetext{
${ }^{3}$ Los derechos vitales están referidos al acceso libre al agua, al aire limpio, a transitar por los territorios sin restricciones, vivir, entre otros.

${ }^{4}$ Cabe hacer notar que muchos ideólogos del neoliberalismo plantearon y plantean el término definitivo del estado de bienestar o del papel del Estado en el desarrollo de políticas sociales. Como lo plantean Kymlicka y Norman (1996, p. 3), ello "no debe verse como expresión de una concepción alternativa de lo que es ser un ciudadano sino como un asalto al propio principio de ciudadanía. Como dice Plant, 'en lugar de aceptar la ciudadanía como una condición política y social, los conservadores modernos han intentado reafirmar el rol del mercado y han rechazado la idea de que la ciudadanía confiere un status independiente del nivel económico' (Plant, 1991, p. 52; Heater, 1990, p. 303; King, 1987, p. 196-198)"

${ }^{5}$ Aquellos que habilitan para participar en decisiones y proyectos que se asumen desde la vida política y el Estado
} 
tiende hoy a girar en torno a la idea de ampliar los ámbitos de acuerdos y generar mecanismos pacíficos para procesar los desacuerdos, se estrella contra la falta de presencia pública y de acceso a las decisiones de una parte importante de la población. Amplios sectores que se encuentran marginados del desarrollo productivo, periféricos en la red territorial y poco representables por los partidos políticos, no acceden al diálogo público, son invisibilizados por los medios de comunicación, no son "verdaderos ciudadanos".

La ciudadanía no es un concepto estático, es evolutivo, dialéctico: entre compromisos y acuerdos, entre status e instituciones, entre políticas públicas e intereses corporativos o particulares, entre lo individual y lo colectivo, entre lo universal y lo cooperativo. Por lo mismo, la ciudadanía es un proceso de conquista permanente de derechos formales y de exigencia de políticas públicas para hacerlos efectivos. La ciudadanía se aprehende, no es una etiqueta que se recibe al nacer y que opera automáticamente - no porque exista un estatus normativo de ciudadano, se es ciudadano. En este sentido se requiere desaprender este concepto institucionalizado de lo que es ser ciudadano, y que también hemos internalizado, para co-crear un nuevo ciudadano. Ello implica co-construirse, es decir, co-construcción de sí mismo, es primero reconocerse como ser humano en convivencia, en relación con un entorno colectivo, comunitario. La ciudadanía no es un concepto unívoco sino más bien doblemente relacional, ya que esta co-construcción se logra a través de la interacción y relación con las/os otros y con la acción social. Esta interacción significa un dialogar con la/el otra/o, actuar con la/el otra/o, sin embargo, este acto relacional es un acto más bien complejo, pues existe una macroestructura cuya base ideológica establece que, para alcanzar "éxitos", debemos situarnos desde un "yo" individual y desarraigado, nucleándonos desde un egocentrismo teñido de narcisismo que invisibiliza al otro, y por tanto, impide todo acto de interacción no coercitiva, de sentido colectivo, de participación ciudadana. 
La ciudadanía implica ser consciencia y acción para el/la otro/a, ser consciencia y acción con la/el otra/o en un proceso no lineal, sino discontinuo, desigual y contradictorio en el tiempo y el espacio. Y que no es más que las relaciones de interacción puestas al servicio de procesos colectivos, de consensos múltiples y de individualidades develadas. Es estar y actuar para las y los otras/os también de manera discontinua, contradictoria y desigual, pero consciente de esta complejidad y ausente de pasividad.

La ciudadanía en sí debe completarse con el entendimiento de la ciudadanía para sí pues ello implica consciencia, consciencia de existencia, de sentido, de acción y de contenido. La ciudadanía existe, está en todos nosotros, es inherente y se vuelve realidad material en la acción social, cuando comprendemos que somos comunidad con intereses, deseos y esperanzas, con palabras y mitos que nos constituyen como humanidad. La ciudadanía es humanidad, es espacio de significaciones pero también de realizaciones, de luchas y derrotas, de derechos y compromisos, y todo ello en un marco de sentido consciente y transformador, liberador, inclusivo y democrático.

Lo anterior no puede integrarse sin contenido, un contenido denunciante, inconforme, crítico, complejo, militante. La ciudadanía es, por tanto, una militancia, militancia democrática, comprometida, participante y es ahí donde la co-construcción toma sentido, donde ser consciencia con el otro se vuelve realidad, se vuelve dialogante, capaz de poder coconstruir consensos aceptando disensos.

El neoliberalismo, con su esencia mercantilizadora, ha instaurado transversalmente el cáncer de la alienación, de la enajenación, de una falsa consciencia ciudadana - no somos ciudadanos en tanto no seamos consumidores con capacidad adquisitiva de bienes y servicios y en cuyo "rol" queda atrapada la persona y su potencial capacidad de construir ciudadanía. El neoliberalismo ha fundido y confundido, ha instaurado e 
institucionalizado una ciudadanía desde la exclusión, desde la violencia, desde la destrucción, desde la riqueza - no todos somos ciudadanos, a veces ni siquiera se nos reconoce nuestra calidad de humanos, no todos tenemos derechos universales y no todos participamos de la construcción social, y es precisamente a esos ciudadanos excluidos a quienes más violentamente se les niega y reprime. Esta concepción de ciudadanía legitimada desde la violencia condena todo aquello que implique participación real de las personas, pues la participación es y debe ser, para ellos, vertical, jerarquizada y ordenada, al igual que la ciudadanía. Por tanto, para levantar esta co-construcción ciudadana se requiere poder liberarse de este rol-consumidor-individual-violentado para transitar a un rol cociudadano-relacional-colectivo donde la voluntad y fuerza colectiva sean capaces de contener las contradicciones, los miedos para que desde ahí surjan nuevas formas co-colectivas de ser ciudadano

Lo anterior implica que el ser social condiciona la ciudadanía, en tanto cuanto, ésta depende de una voluntad personal y colectiva. Es asumir que su existencia económica, política, social y cultural se transforma en un hecho consciente de la situación histórica. Entonces, no hay cociudadanía sino hay acción social de los ciudadanos, donde la acción social no sólo es explicitar la norma de la ciudadanía sino formar parte de las acciones co-ciudadanas, ser parte transformadora del entorno. Existen sectores ciudadanos con una consciencia social de sus derechos más activa que otros y ellos deben ciudadanamente co-construir espacios, denuncias, inclusiones que permitan que la multiplicidad de manifestaciones ciudadanas emerjan y se amplíe no sólo el concepto de ciudadanía sino el comprenderse como ciudadano y lo que ello, como compromiso, implica.

Finalmente, la ciudadanía no es siempre la misma, es dinámica, puede cambiar rápidamente, sobre todo en periodos de movilizaciones sociales. No existe una ciudadanía para siempre, es una co-construcción histórica permanente, participativa, compleja, no lineal, democrática y 
popular. Revertir esta situación de construcción ciudadana implica la relación con formas de conocer, hacer y sentir, es decir, la participación ciudadana es un acto de aprendizaje libre y comunitario y no el impuesto por poderes hegemónicos (considerando que todas las instituciones socializadoras transmiten y enseñan este ser ciudadano individualizado, atemporal, a-espacial, acrítico, mediático, fragmentado, en definitiva, un ser a-social, obsecuente con el modelo de dominación capitalista).

Por lo mismo, esto implica un aprender a interactuar con el otro con un sentido de colectividad y no de individualidad, aprender a desarrollar espacios de interacción y relaciones que no busquen sólo el desarrollo económico ni el bienestar personal, sino la importancia de un desarrollo humano que es más que el desarrollo económico individual, ya que contiene la valoración también de desarrollo social, sustentable, afectivo, comunitario.

Como es un aprendizaje, cabe la co-responsabilidad a espacios micro y macrosociales de socialización como la familia, la escuela, el Estado, que generen un discurso valorativo, propositivo no normativo de la participación ciudadana para construir espacios reales para la re-valorización y ejercicios de acciones ciudadanas. Para esto se hace necesario creer en el poder de la participación ciudadana como base de una nación democrática para la co-construcción de una sociedad libre, justa y donde los co-ciudadanos puedan participar en condiciones de igualdad en el intercambio comunicativo, en el intercambio cultural, en el manejo de la información, en el acceso a los espacios públicos, en la adquisición del conocimiento, en la gestión del Estado y de los gobiernos locales y ejerce[r] la totalidad o parte de sus derechos políticos o sociales [...] de forma independiente o por medio de su pertenencia a una comunidad real o virtual (Robles, 2009, p. 55).

En definitiva, el nuevo co-ciudadana/o debe ser democrático, proactivo, crítico, consciente de su papel como ente y productor de cambios por lo que no se retira de las calles, ejerce presión o fuerza a partir de su 
movilización concreta, involucrado y comprometido con la distribución del acceso al nivel de igualdad social, con su propio proyecto de vida colectivo, con visiones del mundo y prácticas culturales y generador y partícipe de redes sociales que busquen el empoderamiento y la promoción social, un ciudadano comunitario, social, activo y sin olvidar sus compromisos y deberes en la construcción del Estado. Es decir, que se configure un ciudadana/o y una ciudadanía

Cuyo rol vaya más allá de los actos electorales, hacia una intervención efectiva en todos los procesos cívicos y políticos de toma de decisiones sobre asuntos en lo que ésta es afectada directa o indirectamente... Esta forma de concebir y practicar la ciudadanía se apoya, fundamentalmente, en la posibilidad de abrir canales formales e informales de relación entre Estado y los distintos movimientos y agrupaciones de la sociedad civil (Orisón, 2005, p. 63).

\section{Espacio Local y Co- Participación en Políticas Públicas}

La propuesta parte de la base de que la necesidad de participación, para ser extensiva, debe promover desde lo territorial y articularse con lo local, regional, nacional y global, y que ésta sea capaz de manifestar situaciones y necesidades que representan un interés tangible para los ciudadanos. Es decir, una ciudadanía que tenga participación en las políticas públicas, una co-ciudadanía capaz de movilizarse, pero no sólo en la expresión de problemáticas coyunturales, situaciones críticas o necesidades sociales, sino también en la distintas alternativas de solución y estrategias de operacionalización de las políticas públicas. En definitiva, una co-ciudadanía presente en el diseño, ejecución, monitoreo y evaluación de las políticas públicas en su propio ámbito y en la relación con las organizaciones sociales, comunitarias y las instancias del Estado. Lo anterior implica modificar la creencia que nos han impuesto que el único 
actor responsable de las políticas públicas es el Estado La política social tradicional ha estado concebida como una actividad puramente estatal. El Estado lleva a cabo la totalidad de las funciones: financia, diseña, opera y supervisa y, esporádicamente, también evalúa. Todas las funciones están unificadas en un mismo actor (Franco, 2004, p. 2).

Debe considerarse que existen en las administraciones públicas importantes obstáculos de tipo cultural, institucional, legal, económico y organizacional que están dificultando la implantación de prácticas de participación ciudadana en los procesos participativos (Prieto Martín, 2006, p. 21-25). Estos obstáculos se presentan Como resultante de ese campo de fuerzas y factores condicionantes, más allá de los propósitos expresos y tácitos, así como de las motivaciones reales, los resultados y las consecuencias de las iniciativas de Gobierno son siempre inciertas (Tesoro, 2007, p. 58).

En el ámbito municipal, estas barreras se ven agudizadas por otras formas características de ejercer el poder ${ }^{7}$ y que están instauradas como prácticas cotidianas de participación. Entre las más conocidas, encontramos el ritualismo político, el personalismo asistencial o el clientelismo ${ }^{8}$. Por tanto, es un imperativo generar entornos que procuraren prevenir las disparidades participativas que afectan comúnmente a las comunidades (Nielsen, 2006, p. 85).

Es precisamente esta disparidad la que ha llevado a la participación en las políticas públicas a fosilizarse, a renegar de la participación, transformando a los actores sociales en clientes capaces sólo de actuar como consumidores

\footnotetext{
${ }^{6}$ Para mayor información, revisar "Estudio: Estado actual y requerimientos de participación ciudadana en la gestión municipal" elaborado por Sur Consultores.

${ }^{7}$ El ritualismo político está referido a la Cercanía con la comunidad como un símil de participación ciudadana para conservar el poder. El personalismo asistencial se basa en la relación entre el alcalde y un vecino o familia que solicita un beneficio o es asistido en sus necesidades. El clientalismo es un pacto tácito o explícito entre grupos comunitarios y autoridad comunal para recibir beneficios a cambio de lealtad política o electoral a esa autoridad.
} 
de productos y servicios y no como actores sociales con compromisos, exigencias y capacidades para poder co-participar en la toma de decisiones, seguimiento y ejecución durante todo el proceso de la política social.

En este sentido, es necesario desplazar la idea que el Estado es la única autoridad responsable en definir las prioridades de la agenda pública, y por otra parte, los ciudadanos deben asumir que su única función no es sólo "demandar" sus necesidades o problemáticas. Estas posiciones - tanto del Estado como de la ciudadanía - son las que están generando un escenario muy restringido para abrir un proceso de co-construcción Estado/ciudadanía. En este contexto, surge la pregunta de ¿̇uál debe ser el nuevo rol del Estado y de la ciudadanía para constituir una nueva autoridad social para las políticas públicas, desde la perspectiva de la coconstrucción? Si la agenda pública no es co-construida, ello se proyecta a los espacios micro como los gobiernos locales, máxime si reconocemos el espacio local como el ámbito más propicio para el desarrollo de una acción pública local más conectada con las preferencias e intereses de la ciudadanía, permitiendo generar oportunidades insustituibles para impulsar procesos efectivos de co-participación.

En este sentido, los gobiernos locales deberían desarrollar un escalonado proceso de descentralización del gobierno central ${ }^{9}$ pues ambos procesos están fuertemente correlacionados, constituyéndose, además, en un instrumento de recuperación de la eficiencia amenazada o simplemente pérdida, por los costos crecientes de la centralización política, administrativa y económica que muchas veces entrampa procesos, burocratiza trámites y retarda soluciones desanimando a la ciudadanía en sus afanes participativos.

\footnotetext{
${ }^{9}$ Es cierto que en el papel este proceso descentralizador existe pero en la práctica se siguen tomando las decisiones importantes, ya sea económicas, políticas o sociales, en la capital. Por lo que se hace necesaria la búsqueda de una nueva articulación entre Estado, Gobiernos Locales y ciudadanos.
} 
La política pública está, entonces, capturada bajo un paradigma dominante centralizador; concentrado en la toma de decisiones, desincentivador de la participación, con una lógica homogenizante, en el que el Estado establece un imaginario de lo qué es la participación y construcción de la agenda pública, que no necesariamente se corresponde con las demandas ciudadanas ni con las claras expresiones con que la realidad nos interpela. Se hace necesaria una fuerte correlación entre el nivel de participación de la población-objetivo en la formulación e implementación de las propuestas de solución y el grado de éxito en el logro de los objetivos de impacto de los programas y proyectos sociales (Franco, 2004, p. 9), que Ileven a establecer la co-construcción no sólo al nivel formal sino que a la génesis y sentido de las políticas públicas que requieren del reconocimiento del otro como actor relevante en el proceso de co-participación, aunque ello signifique abandonar el espacio de poder desde el cual construye e interpreta el Estado los procesos sociales de participación.

La trascendencia e implicancia que los movimientos sociales tienen en la agenda pública visibiliza distintas problemáticas, necesidades o situaciones emergentes sobre a las cuales el Estado no ha respondido de manera adecuada. Sin embargo, no basta con exponer dichas problemáticas sino que hay que actuar cooperativamente en la búsqueda de soluciones, hacer co-partícipe a las personas de todo el proceso y, en conjunto, buscar mecanismos de co-construcción ciudadana que signifiquen una democratización de los espacios de poder y una transversalidad en la toma de decisiones en el espacio social.

Más aún si la ciudadanía está demostrando activamente querer ser también un actor relevante en la problematización de sus demandas y en los acuerdos logrados, estableciendo, así, la necesidad de una co-construcción Estado-ciudadanía, la cual implique un cambio de "rol" para ambos actores de manera a descentralizar el espacio decisional y 
co-construir la agenda pública-social. Lo que se interpela, lo necesario y urgente es un cambio paradigmático,

[...] que haga imperioso un cierto consenso tanto entre las autoridades gubernamentales con en el conjunto de la sociedad respecto a los objetivos buscados, a los que destinan recursos. Para lograr ese acuerdo social, debe realizarse un amplio intercambio de ideas, en un espacio pluralista. Una vez logrado ese acuerdo, "las acciones que se lleven a cabo de manera técnicamente solvente y con respaldo político. Es en esta etapa que cabe pensar en la Autoridad Social (Franco, 2004, p. 1I).

Lo anterior cobra relevancia en el nuevo escenario social u orden social. Y este acuerdo social, en nuestra propuesta, sólo se alcanza en un verdadero proceso de co-construcción. Para poder materializar esta co-construcción de políticas públicas es imperativo plantearse algunas acciones que, aunque parezcan menores, son de mucha importancia para ir modificando la concepción excluyente y mercantilista de las políticas públicas, a saber:

1. Desarrollar en comunidad mecanismos de participación que posibiliten la incidencia ciudadana en las políticas públicas, cualquiera que sea su ámbito territorial dando poder real a la sociedad, independientemente del nivel en que la participación ciudadana se desarrolle, sea a través de la información, la comunicación, la consulta, la deliberación o la participación verdadera en la toma de decisiones; una co-participación.

2. Generar organización ciudadana co-construida activamente desde lo comunitario/local pues ella posee los diagnósticos, estrategias e impactos de las problemáticas que los conflictúan y será deber del Estado, y en particular de los gobiernos locales, asumir esta nueva realidad para en conjunto co-construir soluciones pues esta conjunción autorregulará y co-construirá metas, tareas, tiempos y acciones. 
3. Poder e injerencia ciudadana en la fiscalización y control de las políticas públicas, especialmente las locales, a través de órganos colegiados y representativos, con equiparidad de miembros (técnicosciudadanos), equiparidad de género y con poder decisional para influir directa o indirectamente en las políticas públicas (Font; Blanco 2003, p. 15).

4. Potenciar y profundizar el ejercicio de co-control social y de coconstrucción de soluciones a través de las contralorías o tribunales, del defensor del pueblo o de la/lo ciudadana/o, y de los organismos estatales y locales especializados.

5. Constitución de gobiernos, particularmente los locales, menos jerarquizados, menos uniformadores, más intersectoriales, más colectivos y comunicacionalmente multidireccionales, es decir, más matriciales y creativos, más descentralizados, con una mayor cocoordinación e intergubernamentalidad ciudadana.

6. Empoderar localmente, a través de organizaciones sociales colegiadas, a la ciudadanía con capacidad de co-articular, co-regular y co-coordinar redes y asociaciones con otras esferas sociales, dirigiendo un proceso interdependiente de elaboración y producción de políticas públicas.

7. Garantizar y asegurar la igualdad y el pluralismo en la confección de políticas públicas desde el ámbito local, para ello es preciso coconstruir resguardos formales pues en la medida que todos los actores, en similares condiciones, pueden participar y dicha participación sea resguardada, considerada e incorporada, la co-construcción se hace material, cobra vida y se fortalece la democracia.

8. Establecer procesos permanentes de autonomización de los gobiernos locales a través del empoderamiento y validación de las or- 
ganizaciones o instituciones locales y ciudadanas para co-construir nueva institucionalidad local cuyo eje central sea la co-participación.

9. Educar en co-ciudadanía, en co-participación pues esta ciudadanía co-construida presenta espacios de libertad para ser ciudadanas/ os y éstos se validan y materializan en la co-construcción con otros, en el impulsar con otros proyectos colectivos fundados en la comunidad y para la comunidad en concomitancia con el poder.

10. Respetar las culturas propias de cada territorio, la diversidad étnica, la diversidad de género, la diversidad sexual, de tal forma que la co-construcción ciudadana recoja y valore la diversidad en función de las políticas públicas.

\section{Palabras Finales}

La ciudadanía involucra dimensiones sociales y culturales vinculadas a los valores de igualdad de oportunidades, calidad de vida, solidaridad, no discriminación presentes en los llamados derechos de tercera generación pero no debe quedarse ahí pues también implica un aprender a interactuar con el otro con un sentido colectivo rescatando la individualidad, aprender a construir espacios de interacción y relaciones que su fin último no sea sólo el desarrollo económico y el bienestar personal, sino la importancia de un desarrollo humano que es más que el desarrollo económico, individual, ya que contiene la valoración también de desarrollo social, sustentable, afectivo, comunitario, democrático e inclusivo. De este modo, la ciudadanía se entrelaza con las referencias identitarias y los reclamos más generales de igualdad ya no sólo en relación al Estado sino en relación con la acción del mercado y todo tipo de dispositivos que promueven la desigualdad. Dirá Nora Aquín: Encontramos múltiples y diarias expresiones y demandas en el espacio público, más o menos orga- 
nizadas, más o menos espontáneas, más o menos explosivas, más o menos masivas (Soto, 2005, p. 99).

Pensada de este modo, y reconociendo la indisociable articulación entre discurso y acción, el ejercicio de la "ciudadanía co-construida" se vuelve imprescindible para la existencia de una sociedad de ciudadanas/ os. Si no existen posibilidades de ejercer ese conjunto de derechos y prácticas expresivas, se debilitan las capacidades y posibilidades de los individuos para constituirse como sujetos de demanda y proposición en múltiples esferas de la realidad, toda vez que la producción de esas demandas y proposiciones resulta impensable sin el ejercicio autónomo del derecho a decidir, a participar, a colaborar, a construir, es decir, a poner en común. Es por eso que la emergencia de la cuestión ciudadana adquiere sentido político. Porque a partir de ella podemos y debemos revelar hasta qué punto la apropiación de los recursos de carácter público por parte del Estado y el mercado son reconocidos como límite sustantivo del ejercicio del conjunto de derechos que hacen democrática a una sociedad.

La participación en este espacio local, entonces, debería recrear nuevas formas de organización de la ciudadanía que permitan su involucramiento activo en la definición de las políticas públicas y en el control de su efectivo cumplimiento. Lo que se facilita pues, de manera incipiente, en estos mismos espacios locales han ido surgiendo nuevas formas orgánicas, valóricas y co-procedimentales de co-participación. Ellas se están constituyendo, junto a las iniciativas gubernamentales del nivel central y local, en el nuevo espacio donde se co-construirá una nueva ciudadanía, una co-ciudadanía que tendrá su extensión, también a la e-ciudadanía. Precisamente será en el espacio local de las políticas públicas donde resulte posible descubrir el sentido real de la co-ciudadanía para, a partir de él, crear y recrear nuevas y eficaces formas de participación y democracia, donde cabe seguir reflexionando sobre cuál(es) es(son) el rol(es) de la ciudadanía y cómo ésta se empodera de los nuevos escenarios de esta co-construcción. 


\section{Referencias}

1. ARTETA, A. El saber del ciudadano: Las Nociones Capitales de Democracia. Madrid: Alianza, 2008.

2. FONT, J.; BLANCO, I. Polis, la Ciudad Participativa: Participar en el Municipio iqué, cómo y por qué? Barcelona: Diputación Barcelona, 2003. (Papers de Participación Ciudadana). Disponível em: <http://www.diba.cat/documents/523487/523545/participacio-fitxers-publicacions_papers-09papers_castpdf.pdf>. Acesso em: 09 jan. 2012.

3. FRANCO, R. Institucionalidad de las Políticas Sociales: Modificaciones para mejorar su Efectividad. Santiago: FLACSO, 2004. Disponível em: < http://bibliotecavirtual.clacso.org.ar/ar/libros/chile/flacso/autoridad.pdf>. Acesso em: 09 jan. 2012.

4. GARCÍA CANCLINI, N. (Coord.) Conflictos Multiculturales de la Globalización. México: Grijalbo, 1995.

5. KYMLICKA, W.; NORMAN, W. El retorno del ciudadano: una revisión de la producción reciente en teoría de la ciudadanía. Cuadernos del CLAEH, Montevideo, n. 75, p. 81-112, 1996.

6. MARSHALL, T. H. Citizenship and Social Class. In: MARSHALL, T. H.; BOTTOMORE, T. Citizenship and Social Class. Londres: Pluto Press, 1992.

7. MOLINA, Y. La gobernabilidad en la Americas. In: BRUNELLE, D. (Org.) Gobernabilidad y democracia en las Americas: teorías y prácticas. Ecuador: Organización Universitaria Interamericana, 2007, p. 59-88.

8. MOLINA, Y.; BRUNELLE, D.; GUDIÑO, P. (Dir.) Desarrollo de Programas Interamericanos sobre Gobernabilidad: Informe preliminar sobre la gobernabilidad en las Américas. [S. I.]: COLAM, 2007.

9. NIELSEN, J. Participation Inequality: Encouraging More Users to Contribute, Alertbox: Current Issues in Web Usability, 2006. ISSN 1548-5552. Disponível em: <http://www.useit.com/alertbox/participation_inequality.html>. Acesso em: 09 jan. 2012.

10. OECD. Promise and Problems of E-Democracy: Challenges of Online Citizen Engagement. Paris: OECD Publications Service, 2004. Disponível em: < http:// www.oecd.org/sti/futures/35176328.pdf>. Acesso em: 09 jan. 2012.

11. ORISÓN, M. (Coord.) La Construcción de la Ciudadanía en el siglo XXI. Barcelona: Octaedro, 2005.

12. PRIETO MARTÍN, P. Sistemas avanzados para la Participación Electrónica Municipal: Ejes Conceptuales para su Diseño. Revista Textos de la Cibersociedad, n. 9, 2006. Disponível em: <http://www.cibersociedad.net/textos/articulo. php?art=91>. Acesso em: 09 jan. 2012. 
13. Quintanilla, M.; Aibar, E. Cultura tecnológica: Estudios de ciencia, tecnología y sociedad. Barcelona: Universidad de Barcelona, 2002. (Serie: Cuadernos del profesorado).

14. ROBLES, J. Ciudadanía digital: Una introducción a un nuevo concepto de ciudadano. Barcelona: Ed. UOC, 2009.

15. RUBIO CARRACEDO, J. Teoría Crítica de la Ciudadanía Democrática. Madrid: Trotta, 2007.

16. TESORO, J. L. La Red RIF-GE: articulación de conocimiento para el gobierno electrónico en las Américas. Enl@ce: Revista Venezolana de Información, Tecnología y Conocimiento, año 4, n. 2, mayo/agosto 2007, p. 43-66.

17. TESORO, J. L. Red Interamericana de Formación en Gobierno Electrónico (RIF-GE): Atención de necesidades formativas con visión de gobernabilidad. In: BRUNELLE, D. (Org.) Gobernabilidad y democracia en las Americas: teorías y prácticas. Ecuador: Organización Universitaria Interamericana, 2007, p.167-191.

18. TURNER, B. Outline of a Theory of Citizenship Sociology. The Journal of the British Sociological Association, v. 24, n. 2, 1990.

19. UNICEF. Comité Español. Educación para la ciudadanía. Madrid, 2005.

Recebido em: 09/01/2012

Aceite final: 23/03/2012 